\title{
Comparison of concentric isokinetic torque peak in active individuals with and without the application of Kinesio Taping
}

\section{Comparação do pico de torque isocinético concêntrico em indivíduos ativos com e sem a aplicação de bandagem elástica funcional.}

Jéssica Kirsch Micheletti ${ }^{1}$, Sérgio Luiz Rodrigues de Souza ${ }^{2}$, Ana Flávia Spadaccini ${ }^{3}$, Rinaldo Bernardelli Junior ${ }^{2}$,

Berlis Ribeiro dos Santos Menossi².

\begin{abstract}
Introduction: Physically active individuals constantly seek resources that can improve their muscle performance, avoid the appearance of lesions and even relapses. Kinesio Taping has been used for both treatment/prevention of injury and to improve functional performance. The isokinetic dynamometer enables rapid quantitative analysis of many parameters of muscle function, being the peak torque the most representative in research and clinical practice. Objective: To compare the concentric peak torque isokinetic in active individuals with and without the application of kinesio taping. Method: 10 male volunteers were evaluated and submitted to the IPAQ questionnaire, where they were considered actives. Then, were realized isokinetic evaluations into steps: Phase Control (without application of elastic taping) and Phase Bandage (with application of placebo and original bandage). The same protocol isokinetic repetitions of 5 to $60 \% / \mathrm{s}$ knee flexion and extension was adopted in all the stages for the reliability and reproducibility of the data. Results: The application of taping in physically active individuals in isokinetic evaluation did not increase the concentric peak torque at $60 \%$ s. Conclusion: Was observed reliability and reproducibility of the results, however, no significant differences were observed in concentric peak torque isokinetic of the quadriceps of active individuals with and without the application of the original kinesio taping and placebo.
\end{abstract}

Keywords: Muscle Strength, Muscle Strength Dynamometer.

\section{RESUMO}

Introdução: Indivíduos fisicamente ativos constantemente buscam recursos que possam melhorar sua performance muscular, evitar o surgimento de lesões e até mesmo recidivas. A bandagem elástica funcional vem sendo utilizada tanto para tratamento/prevenção de lesões quanto para melhorar o desempenho funcional. A dinamometria isocinética possibilita uma rápida análise quantitativa de muitos parâmetros da função muscular, sendo o pico de torque o mais representativo em pesquisas e na clínica. Objetivo: Comparar o pico de torque isocinético concêntrico em indivíduos ativos com e sem a aplicação de bandagem elástica funcional. Método: Foram avaliados 10 voluntários do gênero masculino, e submetidos ao questionário IPAQ, sendo eles ativos. Em seguida, foram realizadas as avaliações isocinéticas divididas em fases: Fase Controle (sem aplicação de bandagem funcional elástica) e Fase Bandagem (com aplicação de bandagem placebo e original). O mesmo protocolo isocinético de 5 repetições a $60 \%$ de flexão e extensão de joelho foi adotado em todas as fases para a confiabilidade e reprodutibilidade dos dados. Resultados: A aplicação da bandagem funcional em indivíduos fisicamente ativos em uma avaliação isocinética não aumentou o pico de torque concêntrico a $60 \%$ s. Conclusão: Observou-se confiabilidade e reprodutibilidade dos resultados, porém, não se observou diferenças significativas no pico de torque concêntrico isocinético de quadríceps de indivíduos ativos com e sem a aplicação de bandagem elástica funcional original e placebo.

Palavras chave: Força muscular, Dinamômetro de Força Muscular.

Corresponding Author: Jéssica Kirsch Micheletti. Address: Rua Takeo Teshima, 127, Rolândia - Paraná, Phone: (43) 99026325, Email: jessicamicheletti@hotmail.com 'Stricto sensu post graduated program, Universidade Estadual Paulista "Júlio de Mesquita Filho" (UNESP), Presidente Prudente (SP), Brazil.

Full list of author information is available at the end of the article.

Financial support: None.

Submission date 13 August 2015; Acceptance date 18 November 2015; Online publication date 27 November 2015 


\section{INTRODUCTION}

A good process for performance improvement and injury prevention depends on the balance of physical training with the athlete's recovery, and the systematization of exercise prescription. Physically active individuals in recreational, amateur or even professional level, seek alternative processes for improved performance, ${ }^{(1)}$ such as taping. ${ }^{(2)}$

In 1996, the Japanese chiropractor Kenzo Kase launched the Kinesio Taping is a functional elastic bandage with its own characteristics when applied on or around the objective muscles assist and give practical support. ${ }^{(2,3)}$ This has been used since then, by physiotherapists in the clinical context as research, ${ }^{(2,4,5)}$ seeking treatment/prevention of injury and improved functional performance. ${ }^{(6)}$

Among the actions of functional elastic bandage, promotes mechanisms such as correction of muscle function strengthening weak muscles, improves blood and lymph circulation, reducing the inflammation process in the affected region, decreased pain neurological suppression, and repositioning of subluxated joints relieving tension and helping to return the desired function of the muscles and fascia and improved strength by promoting a pre muscle contraction. ${ }^{(7)}$

To evaluate muscle function is desirable to use an instrument that enables the generation of quantitative data, objective, valid and reliable as the isokinetic dynamometer. ${ }^{(8-12)}$ The isokinetic dynamometer enables fast quantitative analysis of many parameters of muscle function including peak torque, torque in specific angle, work, power and endurance levels. ${ }^{(12,13)}$ of all these variables, the peak torque has greater representation in research and clinical practice. $^{(12)}$

Therefore, the aim of the study was to compare the concentric isokinetic peak torque in active individuals with and without the application of functional elastic bandage.

\section{METHOD}

This is a field research, qualitative and quantitative crossectional with volunteers considered active by the IPAQ questionnaire, which were evaluated in the Physical Evaluation Laboratory of the Universidade Estadual do Norte do Paraná (UENP) - Centro de Ciência da Saúde (CCS).

The study had as inclusion criteria the volunteer be considered active according to the IPAQ. Exclusion criteria were having undergone surgery to present any orthopedic injury following studied problems that impede the realization of muscle strength, power in a period of less than two hours before the evaluation and having practiced any physical activity 48 hours or less before evaluation .

The sample consisted of 10 active volunteers were male with a mean age $21 \pm 2.1$ years, weight $78.1 \pm 11.1 \mathrm{~kg}$ and height of $1.76 \pm 0.08 \mathrm{~m}$.

\section{Study Design}

All volunteers underwent three times at the same isokinetic assessment protocol, with one week apart between them.

The 1 st assessment was carried out without the application of taping, called Control Phase (CP), made up of the control group (CG).

In the 2 nd assessment, carried out with the same 10 volunteers, began to bandage Phase (BP) where it has been applying the original taping in half of the group, composed of five volunteers appointed as a subgroup, Original Bandage 1 (OB1) and placebo bandage the other half, formed by the remaining five volunteers appointed Placebo Bandage 1 (PB1).

The 3rd evaluation, yet the $\mathrm{BP}$, the volunteers in the 2 nd assessment were with original taping were with taping applied placebo shape, forming the placebo bandage 2 subgroup (PB2) and those who had the use of placebo way, formed the 3rd subgroup that this evaluation we used the taping of original shape, and original banding 2 (OB2).

The design illustrated in Figure 1 below.

\section{Application method of Elastic Bandage Functional}

A specific method for strength increase of $25 \%$ to $50 \%$ strain functional bandage placed over the rectus femoris muscle origin was used for the insertion, to the upper pole of the patella in accordance with the method of Kase et al., ${ }^{(3)}$ precursor of Kinesio Taping method.

The bandage Application was held at the 2 nd battery of assessments (BP) where volunteers came alone in a separate room and the appraiser applied to taping without the knowledge of the voluntary and evaluators, featuring the double-blind method. After the application was held isokinetic test itself. Method also used in the 3rd assessment (BP).

With the group split into two groups of five volunteers in the second and third evaluation, where the application of unique and placebo taping was done, it can evaluate the reliability and reproducibility of the test.

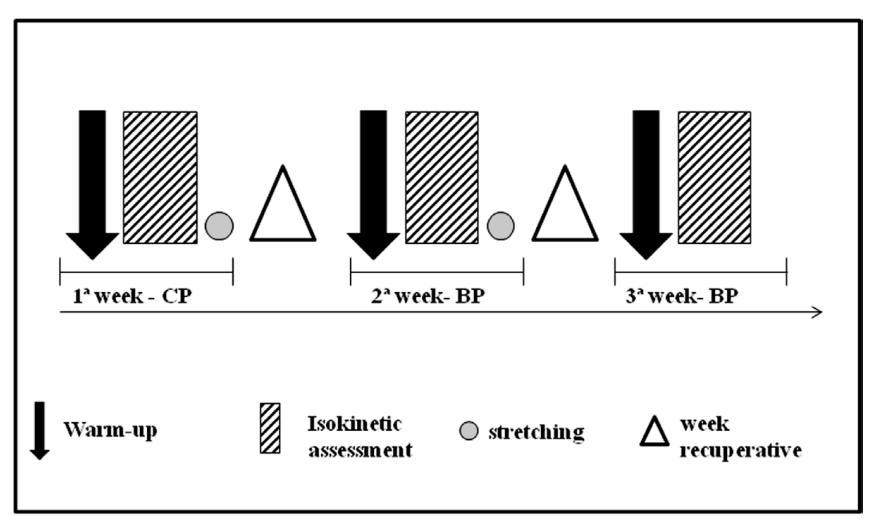

Figure 1. Study Design. 


\section{Isokinetic evaluation}

The evaluations were performed on the isokinetic dynamometer brand Biodex Medical Systems ${ }^{\circledR} 4$, model Biodex Multi-Joint System PRO, with a protocol flexion and knee extension, concentric/concentric (CON/CON). The evaluations were bilateral in a considered slow speed of $60 \%$ s with five consecutive repetitions, starting with the dominant member.

The environment was maintained at a comfortable temperature of 21 to $23^{\circ} \mathrm{C}$, this temperature being maintained throughout the evaluation period. The calibration of the equipment was performed the day before evaluation.

For isokinetic evaluation were taken a few steps. Before assessing the individual was weighed on a digital scale WELMY ${ }^{\circledR}$ brand. The heating was conducted in an exercise bike Monark ${ }^{\circledR}$ mark with an intensity of $50 \mathrm{~J}$ work where the volunteer should maintain a speed between 20 and $25 \mathrm{~km} / \mathrm{h}$ for a period of 10 minutes and this phase in order to prepare voluntary and prevent discomfort during the evaluation. The volunteer was positioned in the isokinetic chair with a straight spine and fully supported by the backrest, $90^{\circ}$ lame femoral flexion, $90^{\circ}$ of knee flexion. The setting of the equipment is obtained by 2 tracks across the chest, a band fixing the region of the iliac crests, a strip maintained fixed the member was evaluated in the thigh to avoid compensatory movements and finally a track to be placed 2 fingers above the calcaneus for fixing the dynamometer to the leg evaluated. Before starting the test the subjects performed three submaximal repetitions at $60 \% \mathrm{sec}$ for familiarization. At this stage the volunteer was instructed to perform the full ranges of motion (flexion and knee extension) with maximum force. The adjustment range of motion for the evaluation was limited to between $100^{\circ}$ of flexion to full extension and pleasant.

After application of the isokinetic evaluation protocol was performed 2 sets of 30 seconds of passive static stretching and then the compressive cryotherapy for 15 minutes on his knees to minimize muscle pain

\section{Statistical analysis}

Statistical analysis was performed based on the Shapiro-Wilk test to analyze the normality of the data of the 1st isokinetic evaluation and to compare these data, we used the Student's $t$ test. The same test was carried out between subgroups of the 2 nd and 3 rd assessment evaluation.

\section{RESULTS}

\section{Biometric sample data}

The average of age, body mass and height are shown in table 1.

\section{Analysis between Groups - Reliability}

Regarding the analysis of the OB1 subgroups with OB2, there were no significant differences $(p=N S)$ for both dominant member (DM) as non-dominant limb (NDM). The mean peak torque (TPM) of OB1 subgroup was $203.6 \mathrm{Nm}$ and $200.9 \mathrm{Nm}$ for DM and NDM, respectively. And the TPM OB2 subgroup was 212.9 Nm 212.1 Nm for DM and NDM for, as shown in Table 2.

The analysis between the PB1 and PB2 subgroups, we can state by Table 3, there were no significant differences ( $p=N S$ ) for both DM and for NDM. TPM The PB1 subgroup for the DM and NDM was $220.6 \mathrm{Nm}$ and $214.4 \mathrm{Nm}$, respectively. And the TPM PB2 subgroup was $226 \mathrm{Nm}$ for the DM and $212.5 \mathrm{Nm}$ for NDM.

No significant differences between the $\mathrm{OB} 1$ and $\mathrm{OB} 2$ subgroups and among the PB1 and PB2 subgroups had to join them to form original bandage group (OB) and the placebo bandage group (BP). Analyzing statistically the FC group, $\mathrm{BO}$ and $\mathrm{BP}$.

\section{Analysis Control Group (CG) and Original Bandage group (OB)}

There were no significant differences $p=N S$ between $C G$ and $\mathrm{OB}$ or for MD and for the NDM. The TPM CG to the DM was $213.6 \mathrm{Nm}$ and the MND of $212.9 \mathrm{Nm}$. To OB TPM group was $207.9 \mathrm{Nm} 206.5 \mathrm{Nm}$ and for DM and NDM, respectively, as shown in Table 4.

\section{Analysis Control Group (CG) and banding Placebo group (PB)}

According to Table 5, in the CG analysis with $\mathrm{PB}$, no significant differences, $p=N S$ for both MD and for MND. The TPM of the CG to the MD was $213.6 \mathrm{Nm}$ and the MND of

Table 1. Biometric data of the sample with standard deviation

\begin{tabular}{cccc}
\hline Sample & $\begin{array}{c}\text { Mean age } \\
\text { (years) }\end{array}$ & $\begin{array}{c}\text { Mean Body } \\
\text { Mass }(\mathbf{k g})\end{array}$ & $\begin{array}{c}\text { Mean Height } \\
\text { (meters) }\end{array}$ \\
\hline 10 & $21.1 \pm 2.1$ & $78.1 \pm 11.1$ & $1.76 \pm 0.08$ \\
\hline
\end{tabular}

Table 2. Average peak torque $\mathrm{B} 1 \mathrm{O}$ and $\mathrm{B} 2 \mathrm{O}$

\begin{tabular}{cccc}
\hline $\begin{array}{c}\text { Torque peak } \\
\text { mean }\end{array}$ & N.m & p & Difference (\%) \\
\hline TPM of DL OB1 & 203.6 & $\mathrm{p}=\mathrm{NS}$ & $4.3 \%$ \\
TPM of DL OB2 & 212.9 & & \\
TPM of NDL OB1 & 200.9 & $\mathrm{p}=\mathrm{NS}$ & $5.2 \%$ \\
TPM of NDL OB2 & 212.1 & & \\
\hline
\end{tabular}

TPM: torque peak mean; N.m: Newton meters; DL: dominant limb; NDL: non dominant limb; OB1: original bandage 1; OB2: original bandage 2; NS: non significant;

\begin{tabular}{cccc}
\multicolumn{3}{l}{ Table 3. Average peak torque B1P and B2P } & \\
\hline $\begin{array}{c}\text { Torque peak } \\
\text { mean }\end{array}$ & N.m & P & Difference (\%) \\
\hline TPM of DL PB1 & 220.6 & $\mathrm{p}=\mathrm{NS}$ & $2.3 \%$ \\
TPM of DL PB2 & 226 & & \\
TPM of NDL PB1 & 214.4 & $\mathrm{p}=\mathrm{NS}$ & $0.8 \%$ \\
TPM of NDL PB2 & 212.5 & & \\
\hline
\end{tabular}

TPM: torque peak mean; N.m: Newton meters; DL: dominant limb; NDL: non dominant limb; PB1: placebo bandage 1; PB2: placebo bandage 2; NS: non significant; 
Table 4. Average peak torque CG and OB.

\begin{tabular}{lllc}
\hline $\begin{array}{c}\text { Torque peak } \\
\text { mean }\end{array}$ & N.m & P & Difference (\%) \\
\hline TPM of DL CG & 213.6 & $\mathrm{p}=\mathrm{NS}$ & $2.6 \%$ \\
TPM of DL OB & 207.9 & & \\
TPM of NDL CG & 212.9 & $\mathrm{p}=\mathrm{NS}$ & $3 \%$ \\
TPM of NDL OB & 206.5 & & \\
\hline
\end{tabular}

TPM: torque peak mean; N.m: Newton meters; DL: dominant limb; NDL: non dominant limb; CG: Control Group; BO: Original Bandage group; NS: non significant

Table 5. Average peak torque CG and PB.

\begin{tabular}{cccc}
\hline $\begin{array}{c}\text { Torque peak } \\
\text { mean }\end{array}$ & N.m & P & Difference (\%) \\
\hline TPM of DL CG & 213.6 & p $=$ NS & $4.3 \%$ \\
TPM of DL PB & 223.3 & & \\
TPM of NDL CG & 212.9 & $\mathrm{p}=\mathrm{NS}$ & $0.2 \%$ \\
TPM of NDL PB & 213.4 & & \\
\hline
\end{tabular}

TPM: torque peak mean; N.m: Newton meters; DL: dominant limb; NDL: non dominan limb; CG: control group; PB: Placebo bandage group; NS: non significant;

Table 6. Average peak torque $\mathrm{OB}$ and PB.

\begin{tabular}{cccc}
\hline $\begin{array}{c}\text { Torque peak } \\
\text { mean }\end{array}$ & N.m & P & $\begin{array}{c}\text { Difference } \\
\text { (\%) }\end{array}$ \\
\hline TPM of DL OB & 207.9 & p=NS & $6.8 \%$ \\
TPM of DL PB & 223.3 & & \\
TPM of NDL OB & 206.5 & p $=\mathrm{NS}$ & $3.4 \%$ \\
TPM of NDL PB & 213.4 & & \\
\hline
\end{tabular}

TPM: torque peak mean; N.m: Newton meters; DL: dominant limb; NDL: non dominant limb; OB: Original bandage group; PB: Placebo bandage group; NS: non significant

212.9 Nm. For BP the MPT group was 223.3 and $213.4 \mathrm{Nm} \mathrm{Nm}$ for DM and NDM, respectively.

\section{Analyses of original bandage group (OB) and Placebo Bandage group (PB)}

There were no significant differences $p=N S$ regarding the analysis between groups with bandage, $\mathrm{OB}$ and $\mathrm{PB}$, both $\mathrm{DM}$ and NDM. OB for the TPM group was 207.9 Nm and 206.5 Nm for DM and NDM, respectively. The PB TPM group was 223.3 Nm 213.4 Nm for DM and NDM to as shown in Table 6.

\section{DISCUSSION}

This study demonstrated that the application of taping in physically active individuals in a isokinetic evaluation does not increase the concentric peak torque. To avoid the psychological effect of banding, the same application was made in a placebo group, but there were no significant changes compared to the original application.

The methodology for reliability verification ensures reproducible results independent of the order that the evaluation was performed, showing no influences familiarization or training. ${ }^{(14)}$
Proof of use of taping through isokinetic evaluation in improving the concentric peak torque is still scarce in the literature. Furthermore, the standardization of testing and application of the evaluated speeds of varieties can lead to inconsistency in the results, making the comparison to similar studies. (14)

The exact mechanism for bandage application associated with the peak torque generation is still unclear. Such events may be due to the work methodology elastic tape tension and wrap application mode.

It is known that the sense of bandage application has influence on muscle tone, is in favor of applying the origin and insertion of muscles evaluated, having an improvement in shrinkage and increasing muscle strength. Regarding the application method, the present study used the bandage from the direction of the source with the insertion of the quadriceps muscle with maximum voltage of $25-50 \%$ of its length.(3) Another study,(15) applied toward the origin and insertion with a maximum voltage of $75 \%$ of its length. There was also a study(16) that put the bandage below the origin of the rectus femoris without tension, mild to moderate ( $25 \%-50 \%)$ over the tape and the end of the two tails without tension. The same happened with another study(17) in which the mode of application was the dominant side Y-shaped, but the tape was stretched to $120 \%$. The three cited studies used the same application protocol that the present study, but in a different application form, which were removed from the guideline suggested by the original manual.(3)

Although other studies use a different form of application with regard to this study also showed no significant differences with respect to the increase in isokinetic torque peak.

In this study there was no significant difference when compared concentric isokinetic peak torque at $60 \% / \mathrm{s}$ with and without use of functional bandage. These findings were also found by other authors. $(18,15,16)$ However, in another study(19) found a significant difference in the speed of 180/s. Another study(20) examined the effect of taping on muscle activity and vertical jump performance in inactive healthy people. There was an increase in the vertical reaction force with application of taping, however, as the jump height was decreased and muscle activity of the medial gastrocnemius tended to increase with the implementation of the taping.

\section{CONCLUSION}

The effectiveness of taping in increasing muscle strength and generating peak torque still needs further investigation. Therefore, there was reliability and reproducibility of the results, however, there was no significant difference in concentric isokinetic peak torque of quadriceps active individuals with and without the application of elastic bandage wraps placebo original and functional. 
It is suggested that further studies are conducted about the subject, involving a population of athletes aiming to standardize the application protocol in order to better results.

\section{AUTHORS CONTRIBUTION}

JKM: Research Project Construction, analysis and interpretation of data and writing of the article. SLRS: Research Project Construction, analysis and interpretation of data and writing of the article. AFS: Research Project Construction, analysis and interpretation of data and writing of the article. RBJ: Critical review. BRSM: Research project design and critical review.

\section{COMPETING INTERESTS}

I declare that no conflict of interest between the authors.

\section{AUTHOR DETAILS}

${ }^{2}$ Universidade Estadual do Norte do Paraná (UENP), Jacarezinho (PR), Brazil. ${ }^{3}$ Stricto sensu post graduated program, Universidade Norte do Paraná (UNOPAR), Londrina (PR), Brazil.

\section{REFERENCES}

1. Pastre CM, Bastos FN, Netto Júnior J, Vanderlei LCM, Hoshi RA. Métodos de recuperação pós-exercício: uma revisão sistemática. Rev Bras Med Esporte. 2009;15(2).

2. Kase K, Tatsuyuki H, Tomoko O. Development of Kinesio tape. Kinesio Taping Perfect Manual. Kinesio Taping Association. 1996;6(10):117-8

3. Kase K, Wallis J, Kase T. Clinical therapeutic aplications of the kinesio taping method. (2nd edition). Kinesio Taping Association, USA, LLC. 2003.

4. Jaraczewska $\mathrm{E}$, Long $\mathrm{C}$. Kinesio ${ }^{\circledR}$ taping in stroke: Improving functional use of the upper extremity in hemiplegia. J. Top stroke rehabil. 2006;13:31-42.

5. Morini Jr N. Bandagem terapêutica. In: Cury VCR, Brandão MB. Reabilitação em paralisia cerebral. Rio de Janeiro: Med Book; 2010.

6. Kneeshaw D. Shoulder taping in the clinical setting. J Body w Mov Ther. 2002;6:2-8.

7. Sijmonsma J. Taping Neuro Muscular Manual. 1aed. Portugal: Cascais. p. $13-18,2007$
8. Jiménez FH, Díaz JG, Montes JV. Técnicas instrumentales de diagnóstico y evaluación en rehabilitación. Dinamometría isocinética. Rehabilitación. 2005;39:288-96.

9. Fonseca ST, Ocarino JM, Silva PLP, Bricio RS, Costa CA, Wanner LL. Caracterização da performance muscular em atletas profissionais de futebol. Rev Bras Med Esporte. 2007;13:143-7.

10. Vilaseca JC, Figuera RG. Aplicaciones clínicas de las pruebas biomecánicas: mitos y realidades. Rehabilitación. 2010;44:195-8.

11. Edouard P, Beguin L, Fayolle-Minon I, Degache F, Farizon F, Calmels P. Relationship between strength and functional indexes (Rowe and Walch-Duplay scores) after shoulder surgical stabilization by the Latarjet technique. Ann Phys Rehabil Med. 2010;53:99-105.

12. Kannus P. Isokinetic evaluation of muscular performance: implications for muscle testing and rehabilitation. Int J Sports Med. 1994;15:11-8.

13. Deslandes S, Mariot JP, Serveto S. Offset of rotation centers creates a bias in isokinetics: A virtual model including stiffness or friction. J Biomech. 2008;41:2112-20.

14. Terreri ASAP, Greve JMD, Amatuzzi MM. Avaliação isocinética do joelho do atleta. Revista Brasileira Medicina do Esporte. 2001;7(5).

15. Wong OM, Cheung RT, Li RC. Isokinetic knee function in healthy subjects with and without kinesio taping. Phys Ther Sport. 2012 Nov;13(4):255-8.

16. Vercelli S, Sartorio F, Foti C, Colletto L, Virton D, Ronconi G, et al. Immediate effects of kinesio taping on quadriceps muscle strength: a single-blind, placebo-controlled crossover trial. Clin J Sport Med. 2012 Jul;22(4):31926.

17. Fu TC, Wong AM, Pei YC, Wu KP, Chou SW, Lin YC. Effect of kinesio taping on muscle strength in athletes - a pilot study. J Sci Med Sport. 2008 Apr;11(2):198-201.

18. Vithoulka I, Beneka A, Malliou P, Aggelousis N, Karatsolis K, Diamantopoulos $K$. The effects of Kinesio-Taping ${ }^{\circledR}$ on quadriceps strength during isokinetic exercise in healthy non athlete women. Isokinetics and Exercise Science. 2010;18(1):1-6.

19. Aktas $G$, Baltaci G. Does kinesiotaping increase knee muscles strength and functional performance? Isokinet Exerc Sci. 2011;19:149-155.

20. Huang CY, Hsieh TH, Lu SC, Su FC. Effect of the Kinesio tape to muscle activity and vertical jump performance in healthy inactive people. Biomed Eng Online. 2011 Aug 11;10:70. 